\title{
LA ARISTOTELIZACIÓN Y PLATONIZACIÓN DE PARMÉNIDES POR SIMPLICIO
}

\author{
NÉstor LUIS CORDERo \\ Universidad de Rennes 1, Francia \\ Ministerio de Ciencia e Innovación, España \\ nestor.luis.cordero@gmail.com
}

\begin{abstract}
La dificultad de captar el pensamiento de Parménides llevó a los intérpretes ya en la Antigüedad a encarar su filosofía según esquemas de pensamiento posteriores. Fue el caso de Aristóteles, cuya interpretación fue heredada por su discípulo Teofrasto y por sus comentadores, especialmente Simplicio. Simplicio, neoplatónico y aristotélico a la vez, propuso una interpretación, fuertemente dualista (dominada por la dicotomía sensible/inteligible), que no se encuentra en las citas recuperadas. En 1789 G.G.Fülleborn, inspirándose en Simplicio, propuso una división del Poema en dos "partes", aceptada hoy en forma unánime, y que debe ser revisada y rechazada con urgencia.
\end{abstract}

Parménides / Simplicio/ Aristóteles / dóxa / Fülleborn

\section{THE ARISTOTELISATION AND PLATONISATION OF PARMENIDES BY SIMPLICIUS}

The difficulty in understanding Parmenides' thought has led the interpreters, from Antiquity onwards, to study his philosophy according to later schemes of thought. It was the case of Aristotle, whose interpretation will be inherited by his disciple Theophrastus and his commentators, specially Simplicius. Simplicius, Neoplatonic and Aristotelian at the same time, proposed an interpretation strongly dualistic (dominated by the alternative intelligible/sensible) that we cannot find in the literal quotations that have been recuperated. It was in 1789 that G.G.Fülleborn, inspired on Simplicius, proposed a division of the Poem in two "parts", division accepted unanimously today. This division should be urgently reviewed and rejected.

Parmenides / Simplicius / Aristotle / dóxa / Fülleborn 
C omo es sabido, los textos originales de los filósofos llamados "presocráticos", salvo mínimas excepciones ${ }^{1}$, se perdieron. Los mal llamados "fragmentos" son en realidad citas de pasajes de dichos libros encontradas en el interior de obras posteriores que tuvieron mejor suerte ya que, completas o sólo en parte, llegaron hasta nosotros. Es sabido también que desde fines del siglo $\mathrm{XVI}^{2}$ comenzaron los intentos por extraer de estas obras las citas de los textos perdidos, con el objeto de reconstruir -evidentemente, sólo en parte, pues los pasajes que nadie citó se perdieron irremediablemente- las obras de los filósofos anteriores a Sócrates. Se considera que esta tarea descomunal de "recuperación" finalizó en 1903 con la publicación del trabajo clásico de H. Diels Die Fragmente der Vorsokratiker.

Este estado de cosas dificulta notablemente la interpretación del pensamiento de los primeros filósofos, y en todos los casos el intérprete debe apoyarse en autores o comentadores de la Antigüedad que poseían los textos completos. No queda otra solución, pero el investigador actual debe ser consciente de que avanza en un terreno minado y que el menor paso en falso -por ejemplo, aceptar ciegamente la opinión del comentador- puede tener consecuencias trágicas. Como es imposible encontrar una receta infalible, desde hace años quien escribe estas líneas ha decidido ser víctima voluntaria de un prejuicio: atenerse rigurosamente a los pocos textos auténticos recuperados literalmente, y "torturarlos"3 hasta que confiesen su significado. Evidentemente, nada asegura que la interpretación a la que se llegue casi veinticinco siglos después de su escritura será la correcta, pero tampoco lo será la que surja de intérpretes que suelen estar inmersos en polémicas entre escuelas rivales y que en más de un caso no se interesan "científicamente" en el estudio de un texto, sino sólo en exponer o polemizar contra las consecuencias "actuales" de las ideas originales. La interpretación de Heráclito por parte de Platón es un caso sintomático.

Puede objetarse que nuestra posición no tiene en cuenta que los comentadores de la Antigüedad poseían los textos originales completos. Es verdad. Pero es verdad también que las citas recuperadas que leemos hoy formaban parte de esos textos, y que sería inimaginable que un autor hubiese afirmado ciertas ideas en los textos perdidos (pero conocidos por los comentadores antiguos) y otras en los textos recuperados. Como veremos, es precisamente esta situación la que encontraremos en Parménides.

1 Entre ellos, los discursos de Gorgias, el papiro que contiene el llamado fr. 44 de Antifonte y el texto conocido como "el Empédocles de Estrasburgo".

2 El primer intento, aunque parcial, fue el de Henri Estienne (1573).

3 Platón utiliza este verbo, basanízo, cuando analiza el lógos de Parménides en Sof. $137 b 1$. 
Es verdad que el riesgo de cometer anacronismos es evidente, pero debe recordarse que la filosofía de Parménides fue difícil de comprender ya en su tiempo. Sus pseudo-herederos, Zenón de Elea y Meliso, no parecen haber captado la originalidad del Poema: en el primero no hay el más mínimo eco del mismo ${ }^{4}$, y si Platón no los hubiese asociado, tanto en el Parmenides como al comienzo del Sofista, ambos hubiesen pasado a la historia como filósofos independientes. Respecto de Meliso, su inclusión de tò ćóv en el espacio y en el tiempo ${ }^{5}$ es ya una prueba evidente de incomprensión. Platón mismo, que confiesa su admiración por Parménides ${ }^{6}$, en un pasaje abundantemente citado del Teeteto escribió que "temo que no comprendamos lo que [Parménides] dice y, mucho más, que se nos oculte qué estaba pensando cuando lo dijo" (184a). Y Aristóteles -ya nos ocuparemos de su interpretación- presenta un Parménides cuya semejanza con el Parménides que surge de los pasajes recuperados del Poema es, como se dice en algunos filmes, pura coincidencia. Ante estas dificultades, es difícil de evitar la tentación, ya en la Antigüedad, de querer interpretar el esquema dicotómico del Poema (que está sin duda presente en los textos que poseemos) en función de los consabidos esquemas platónicos dualistas que se impusieron (incluso entre quienes los criticaron) durante toda la Antigüedad. Simplicio cayó en esta tentación, pero lo hizo en tanto fiel comentador de Aristóteles, ya que, en realidad, todo comenzó con Aristóteles.

No caben dudas de que Aristóteles pudo poseer el texto completo del Poema, pero ello no impide que, en función de las citas recuperadas del texto originario, podamos sostener que su interpretación es, en el mejor de los casos, ambigua o que está demasiado influenciada por su propia filosofía. El trabajo clásico de H. Cherniss había ya señalado la parcialidad de los enfoques de Aristóteles, que suele verter en sus propias categorías el pensamiento de sus antecesores. En el caso de Parménides, por ejemplo, nada asegura que este haya podido afirmar, como dice Aristóteles,

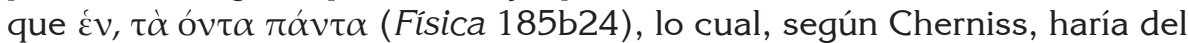
عóv parmenídeo "un concepto que unifica el mundo físico"7. Siempre respecto de la interpretación aristotélica de Parménides, Suzanne Mansion es más condescendiente y escribió que "si se quiere comprender la actitud de Aristóteles respecto de los Eleatas, hay que intentar observarlos a través

4 Ver CORDERO (1988: 100-126).

5 Ver el sutil trabajo de Barnes (1979: 1-21).

6 En el Teeteto Platón trata a Parménides de "venerable y temible" (183e), y Simplicio constata que Platón admiraba $(\theta \alpha v \mu \alpha ́ \zeta \zeta v)$ a Parménides a tal punto que le parecía que

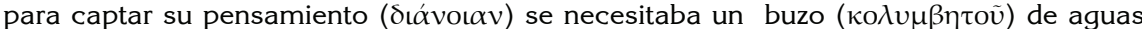
profundas (36.32), lo cual es una verdadera confesión: el texto del Poema es, para Platón, difícil de captar.

7 ChERNISS (1935: 65). 


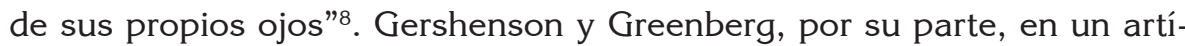
culo clásico, llegan a la misma conclusión pero son menos diplomáticos y afirman que "la totalidad del análisis [de Aristóteles] presupone su propia manera de pensar acerca del lenguaje, la lógica y la realidad física"9.

Veamos algunos ejemplos concretos. En Met. 986b19 Aristóteles afir-

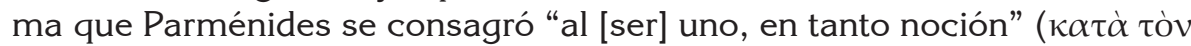

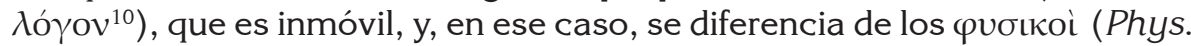
184b17). Es así como tanto él como Meliso se expresan "oủ $\varphi v \sigma \iota k o l$ (De Caelo, 298b18). Pero, a diferencia de otros filósofos que también sostuvieron la existencia de un ser uno e inmóvil, Parménides "decidió no reconocer sólo una, sino, en cierto modo $(\pi \omega \varsigma)$ dos causas" (Met. 984b4).

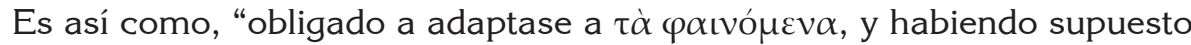
que, según el $\lambda o ́ \gamma o \varsigma$, [el ser] es uno, si bien, según la sensación, es múltiple, [Parménides] sostuvo dos causas y dos principios, el calor y el frío, es decir, el fuego y la tierra, y colocó a uno de ellos como ser, y al otro como no-ser" (Met. 986b31). En este caso Parménides habría actuado como los otros y sería dualista.

En estas escasas referencias de Aristóteles a Parménides se basa la interpretación de Simplicio, pero nada segura que la misma sea correcta. $\mathrm{H}$. Baltussen, autor de un trabajo titulado precisamente Phisosophy and Exegesis in Simplicius ${ }^{11}$ sostiene que en este autor se detectan "modern projections about quotations from written sources". Es así como Simplicio encuentra en Parménides dos "objetos" de estudio, el Ser-Uno, captado por el $\lambda$ ó $о \varsigma$ (y para referirse a este objeto "pensable" Simplicio hará uso y abuso de la expresión tò vontóv), y los fenómenos sensibles (en Simplicio, $\tau \dot{\alpha} \alpha \grave{i} \sigma \theta \eta \tau \dot{\alpha})$, captados por los sentidos. Pero esta interpretación de Simplicio tuvo un efecto secundario inesperado en el caso de Parménides: la división del Poema en dos "partes", la Alétheia y la Dóxa. Veamos qué es lo que ocurrió.

Dado que los textos de los primeros filósofos que se pudieron recuperar están constituidos, casi todos, por frases aisladas que no sugieren en qué pasaje, capítulo o parte del libro perdido hubiesen podido encontrarse, los investigadores no pretenden, en general ${ }^{12}$, reconstruir el texto perdido en su orden original, forzosamente desconocido. Parménides, no

8 Mansion (1949: 165).

9 Gershenson-GREENBERG (1962: 138).

10 Hemos preferido la traducción de lógos por "noción" sobre la base de la definición propuesta en los Segundos Analíticos: "Como consecuencia de la repetición de una misma sensación se forma un lógos" (100a2), o sea, una "noción".

11 Baltussen (2008: 27).

12 Una excepción sería el caso del intento actual de S.Mouraviev de reconstruir el "libro" de Heráclito. 
obstante -e inexplicablemente-, parece ser una excepción. En realidad, lo único que se sabe en forma concreta es que el Poema comenzaba con una suerte de introducción, ya que Sexto Empírico, la única fuente del texto conocido hoy como "fragmento 1" dice, al citarlo, que "así comenzaba el Poema de Parménides" (Adv.Math. VII.111). Pero luego de esta introducción, a la que se llama Proemio, se admite hoy en forma unánime que el Poema constaba de una primera parte conocida como Alétheia, y de una segunda parte, llamada la Dóxa.

Esta división del Poema en tres partes tiene fecha de nacimiento: 1795. En ese año G. G. Fülleborn publicó el primer libro consagrado exclusivamente a Parménides ${ }^{13}$ y en él propuso dicha tripartición, que, como veremos, se inspira en Simplicio. Esta tripartición fue modificada sólo en pequeños detalles por C.A.Brandis ${ }^{14}$ y por S.Karsten ${ }^{15}$, y; finalmente, fue sacralizada por H.Diels ${ }^{16}$. En función de esta estructura, ciertos fragmentos ${ }^{17}$ (fr. 2 a fr. 8.51) pasaron a formar parte de la Alétheia, y otros (fr. 8.52 a fr. $19)$, de la Doxa. Este esquema se impuso como una evidencia irrefutable.

Ya en 1899 F.Susemihl publicó en Philologus (58) un artículo con el título de Zum zweiten Theile des Parmenides, pero quien consagró definitivamente esta estructura del Poema fue K.Reinhardt, en su clásico trabajo sobre Parrménides ${ }^{18}$. El libro privilegia a tal punto las "partes" del Poema que su primer capítulo se titula ya "El lazo de unión entre las dos partes (Teilen) del Poema", y, consecuentemente, los capítulos siguientes tienen como título "Der erste Teil" y "Der zweite Teil".

Antes de proseguir el análisis del origen de esta manera de agrupar los diecinueve fragmentos de Parménides encontrados hasta hoy, debemos reconocer que ella supone una interpretación de la filosofía del autor, interpretación que no dudamos en calificar de anacrónica y de perniciosa. Nunca sabremos en qué orden se encontraban los fragmentos en el texto original, pero no caben dudas de que, como Parménides no es responsable de esta estructura actual, toda referencia a una "primera parte" del Poema o a una "segunda parte" compromete sólo al intérprete, no al Eléata.

Antes de ocuparnos de las razones que llevaron a Fülleborn a proponer su esquema tricotómico, se impone decir dos palabras sobre los dos intentos de reconstrucción del Poema anteriores al suyo. Sus autores fue-

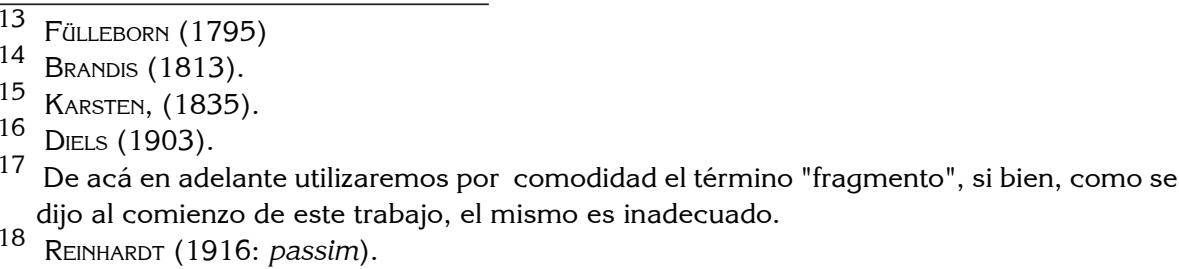


ron Henri Estienne (1575) y Joseph J. Scaliger (entre 1597 y 1600). Estienne presentó sesenta y siete versos auténticos agrupados en función de la fuente que los había citado (Plutarco, Sexto, etc.), sin pretender restablecer un hipotético orden originario. Scaliger, por su parte, llevó a cabo una tarea titánica, ya que consiguió reunir ciento cuarenta y nueve versos, casi la totalidad de las citas conocidas hoy. Como es sabido, el único defecto del trabajo inmenso de Scaliger fue el siguiente: permaneció inédito durante más de cuatro siglos, hasta que finalmente conseguimos publicarlo en $1982^{19}$. Al igual que Estienne, Scaliger citaba los fragmentos en función de su fuente, sin intentar reproducir una estructura originaria que, forzosamente, sería imposible de descubrir.

Volvamos a Fülleborn. Después de reproducir la extensa cita de Sexto conocida como Proemio, su trascripción de los fragmentos comienza con una "Rationale Kosmologie ${ }^{20}$, oder Vernunfterkenntniss vom Wesen der

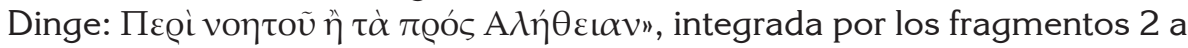
8 (hasta el verso 52). Y luego esta primera parte es seguida por la sección "Sinnliche Erkenntniss vom Wesen der Dinge: Tà $\pi$ @ò $\varsigma$ ó $\xi \alpha v "$, constituida por los fragmentos 8 (a partir del verso 53) hasta el fragmento 18 (ya que por entonces se ignoraba la existencia del actual "fragmento 19").

De la presentación de cada parte se deduce claramente que ambas fueron establecidas en función de los criterios utilizados para captar "la esencia de las cosas": el pensamiento o la razón, y la sensación. Y Fülleborn aclara, en el prólogo de su libro, que "ita dividit carmen Parmenidis Simplicius" "“Así dividió Simplicio el Poema de Parmenides") (p. 54). Simplicio, inspirador de Fülleborn, es entonces el responsable de la división actual del Poema de Parménides en una sección que se ocupa de "lo inteligible", ámbito que concierne a "la verdad", y otra sección consagrada a "lo sensible", sobre el cual sólo hay "opiniones" (dóxai). Éste es el status quæestionis actual. Nuestra modernidad ha efectuado sólo algunos liftings para rejuvenecer esta dicotomía: como el objeto inteligible por excelencia es "el Ser", suele llamarse a la primera parte "Vía de la Verdad, o del Ser", y como lo sensible se asimila a los fenómenos, la segunda parte sería la "Vía de las Apariencias"21

Como la paternidad de Simplicio reivindicada por Fülleborn es, como veremos, correcta, nuestro trabajo se concentrará de acá en adelante

19 Ver CoRdero (1982: 391-398).

20 Es probable que por "cosmología racional" Fülleborn, influido por la filosofía kantiana que está en su apogeo cuando él publica su libro, haga alusión simplemente al conocimiento inteligible (no sensible) de las "cosas" ("Dinge"). En 1800 Fülleborn escribió un libro titulado Immanuel Kant. Nebst einigen Bemerkungen über die Kantische Philosophie.

21 En la mayor parte de los estudios escritos en inglés se habla de la "Way of Seeming" 
en la interpretación simpliciana de la filosofía de Parménides ${ }^{22}$. Evidentemente, cuando Fülleborn escribió que "ita dividit carmen Parmenidis Simplicius" pensó sin duda en la frase del comentador que clausura su cita de los primeros 52 versos del fragmento 8, consagrados a los atributos del ó :

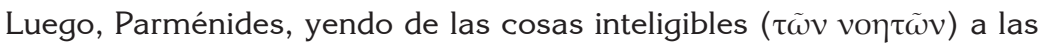
cosas sensibles ( $\tau \dot{\alpha} \alpha \hat{i} \sigma \theta \eta \tau \dot{\alpha}$ ), o sea, como él mismo dice, de la $\alpha \lambda \eta \dot{\theta \varepsilon \iota \alpha}$ a la $\delta o ́ \xi \alpha$, afirma:

"Acá termino para ti el razonamiento fiable y el pensamiento acerca de la verdad. A partir de acá, las opiniones de los mortales aprende, escuchando el orden engañoso de mis palabras"23.

Y él mismo, como principios de las cosas engendradas, a la manera de elementos ( $\sigma \tau о \chi \chi \varepsilon เ \omega ́ \delta \varepsilon เ \varsigma)$, coloca la primera oposición, a la que llama luz y oscuridad, $<0>$ fuego y tierra, o denso y raro, o mismo y otro, diciendo de inmediato estas palabras que se citan a continuación:

Ellos establecieron dos puntos de vista para nombrar a las formas, a los cuales no unificaron necesariamente ${ }^{24}-\mathrm{y}$ en esto se equivocaronDistinguen una forma enfrentada a ella misma, y ofrecen de ellas pruebas separadas las unas de las otras: por un lado, el fuego etéreo de la llama, suave y muy liviano, completamente idéntico a sí mismo, pero no idéntico al otro; por otro lado, aquello que es en sí su contrario, la noche oscura, forma espesa y pesada"25. (Simplicio, Phys. 30.14-31.2) ${ }^{26}$.

La extensa cita de Simplicio contiene el pasaje en el cual Parménides abandona la presentación de los ớ $\mu \alpha \tau \alpha$ del hecho de ser ( $\varepsilon o ́ v)$ y pasa a

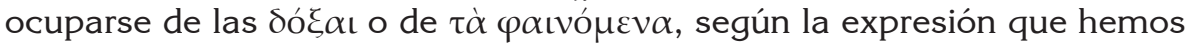
encontrado en Aristóteles (Met. 986b31). Según Simplicio, el discurso y el pensamiento sobre la verdad, que concluye en el verso 8.50 , forma parte de "lo inteligible". Las referencias de Simplicio a la asimilación de lo que él llama el Ser-Uno de Parménides a "lo inteligible" son muy numerosas.

22 Ver el trabajo de Stevens (1990)

23 En el caso de Parménides, utilizamos como texto y traducción nuestra edición (ver CORDERO, 2005). La cita corresponde a los versos 50-52 del fr. 8.

24 Otra traducción posible es: "Uno de los cuales no es necesario".

25 Parménides, fr. 8.53-9.

26 En el caso de Simplicio, utilizamos la versión más moderna del mismo (que tiene ya casi un siglo y medio de existencia), elaborada por Diels (1882-5). 
Basta mencionar unos pocos ejemplos. Cuando Simplicio cita el verso que se refiere a la inmovilidad de tò ćóv (8.26) dice que así habla Parméni-

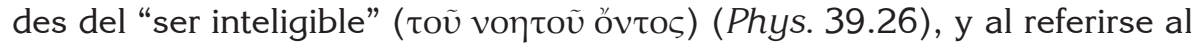

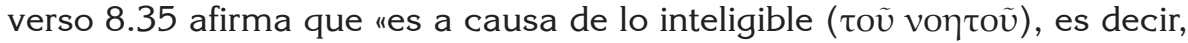

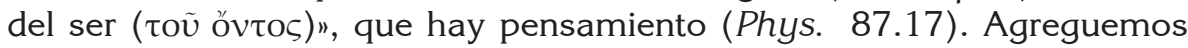
que en una alusión a Alejandro de Afrodisia, Simplicio dice que también éste reconoce en Parménides la inmovilidad del ser "en el pasaje sobre la

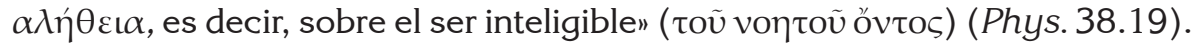
Y finalmente, antes de citar los últimos versos del fragmento 8, Simplicio escribe que Parménides acaba de finalizar su "discurso sobre lo inteligible"

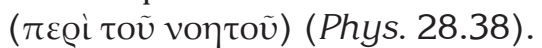

La asimilación de la dóxa a lo sensible es también recurrente. "Par-

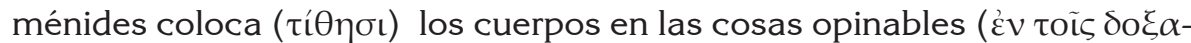

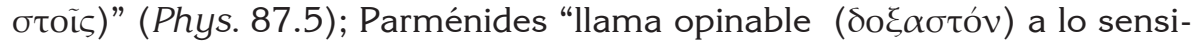

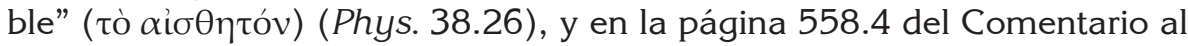
De Caelo Simplicio dice que a partir del verso 8.52 Parménides va a ocuparse "de las cosas sensibles" ( $\tau \tilde{\omega} v \alpha i \sigma \theta \eta \tau \tilde{\omega} v)$.

Finalmente, la asimilación de lo inteligible al discurso sobre el ser y la verdad, y de lo sensible a la dóxa reaparece cada vez que Simplicio cita o comenta los versos 50-2 del fragmento 8, que separan el fin de un discurso

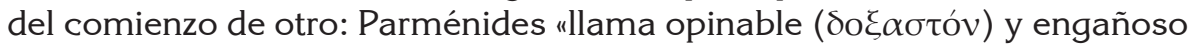
( $\dot{\alpha} \pi \alpha \tau \eta \lambda o ́ v)$ a este discurso ( $\lambda$ ó $\gamma o v)^{27}$, aunque no completamente falso, sino

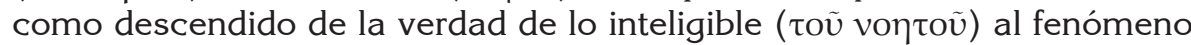

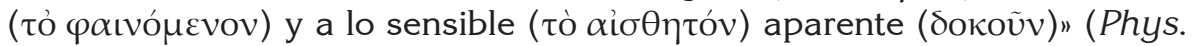
39.10). Y otro tanto leemos en el Comentario al De Caelo: "para completar

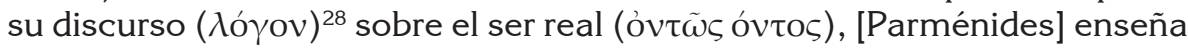
lo siguiente a propósito de las cosas sensibles ( $\tau \tilde{\omega} v \alpha \hat{\imath} \sigma \theta \eta \tau \tilde{\omega} v) \ldots . "$ (558.3).

He llegado el momento de analizar esta interpretación de Simplicio, inspiradora de Fülleborn y, por intermedio de éste, vox docti en los estudios parmenídeos actuales, que encara la filosofía de Parménides como una combinación de un criterio inteligible y de un criterio sensible. No dudamos en afirmar -e intentaremos demostrarlo- que Simplicio aplica a Parménides un esquema aristotélico-platónico que nada tiene que ver con la filosofía del Eléata, entre otras cosas -ivaya novedad! - porque Parménides es anterior a Platón y a Aristóteles. Simplicio posee el Poema de Parménides -él mismo lo

27 Tanto en este pasaje como en otros textos paralelos, Simplicio no duda en aplicar el término

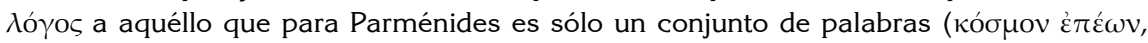

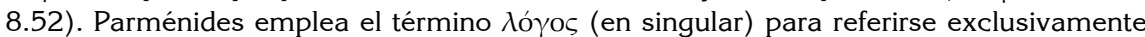

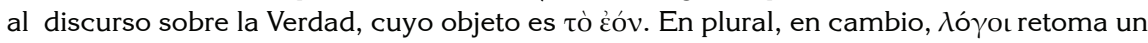
cliché homérico (Odisea, I.56) (ver fr. 1.15).

28 Ver nota anterior. 
dice ${ }^{29}$-, lo cita abundantemente -por suerte: gracias a él poseemos $65 \%$ del texto original- pero fiel a sus maestros, Aristóteles y Platón, cuyas filosofías intenta hacer coincidir, no puede escapar a su influencia.

Hay que reconocer que Simplicio no fue el primer filósofo en sucumbir al canto de las sirenas de los esquemas aristotélico-platónicos. Escasos son los testigos de la filosofía de Parménides anteriores a éste y a Proclo, pero Plutarco parece haber caído en la misma trampa que Simplicio. En efecto, antes de citar los últimos versos del texto que hoy conocemos como

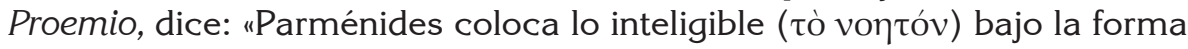

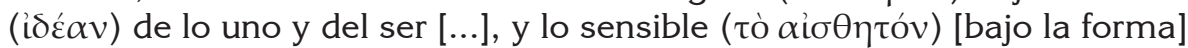
de lo desordenado y lo móvil". Cita luego el verso que se refiere a la imperturbabilidad del corazón de la verdad (1.29), que expone "lo inteligible

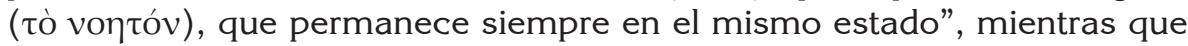
los versos siguientes presentan les opiniones de los mortales, en las cuales no se puede creer (1.30-1), porque, según Plutarco, están "en relación con todos los asuntos que cambian, las afecciones y las desigualdades" (Adv. Colot. 13p. 1114D = 28 A 34 DK). Como en el caso de Simplicio más tarde, ya Plutarco asimila "el ser" a "lo inteligible" y las dóxai a "lo sensible".

Analicemos ahora la dicotomía "sensible/inteligible", que es básica en este tipo de interpretación. Su origen se encuentra ya en Aristóteles, cuando admite que, por un lado, Parménides se ocupó del ser, $\kappa \alpha \tau \dot{\alpha}$

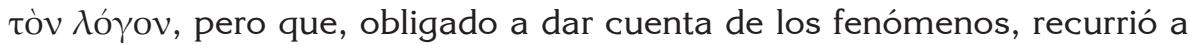
la sensación y propuso dos principios (Met. 986b31). Tanto Plutarco, en el breve pasaje citado, como Simplicio, en la totalidad de su comentario, interpretan la filosofía de Parménides como un intento por explicar dos tipos de realidades, o, según la fórmula de A.Stevens, "deux niveaux de réalité" ("dos niveles de realidad") ${ }^{30}$ : el de "las cosas inteligibles" y el de "las cosas sensibles". Cada tipo de realidad es captada por un medio diferente: el pensamiento, la primera, y la sensación, la segunda. El contenido captado por el pensamiento, que es tò ćóv, es considerado verdadero, pero

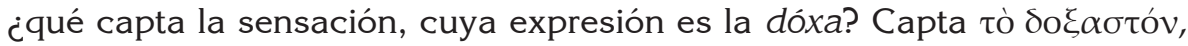

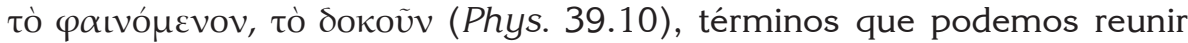
bajo la apelación de "las apariencias" ${ }^{31}$. Es precisamente el término (y la noción) de dóxa (que se encuentra tanto en Parménides como en Platón) la que, según nuestra opinión, invitó a Simplicio a aplicar a Parménides

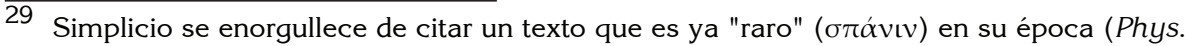
144.28)

30 SteVens (1990: 68).

31 Es su traducción del verso 8.52 Stevens traduce dóxaipor "opinions", pero cuando comenta el pasaje (1990: 67) dice que en ese verso Parménides pasa "de la vérité à l'apparence" ("de la verdad a la apariencia"). 
un esquema interpretativo de origen platónico, y a pretender encontrar en Parménides el dualismo básico que caracteriza a la filosofía platónica (si bien el mismo Platón hizo esfuerzos titánicos para suprimirlo en la última etapa de su filosofía, pero esta es otra cuestión). Esta verdadera obsesión de Simplicio lo llevó a no reparar en ciertos puntos fundamentales que se encuentran en los textos parmenídeos que él mismo cita, y a los cuales Aristóteles no hace alusión.

Estos puntos son los siguientes: (a) el propósito general del Poema de Parménides; (b) el significado de doxa en el Poema; (c) la paternidad de la doxa.

Analicemos estos tres puntos.

(a) Parménides se propone describir dos tipos de conocimiento posibles, y no dos tipos de realidades a conocer. El "objeto" que Parménides quiere explicar, como todos sus colegas presocráticos anteriores y poste-

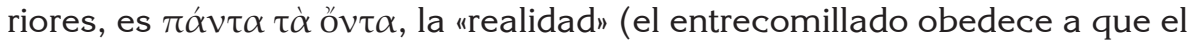
término no existe en griego). Para Parménides hay dos maneras (ódoí) ${ }^{32}$ de hacerlo: o bien, o mal. El discurso que capta las cosas tal como son es convincente, pues acompaña a la verdad (fr. 2.4); el conjunto de pala-

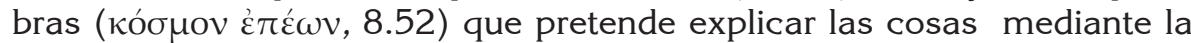
postulación de principios contradictorios no posee verdadera convicción

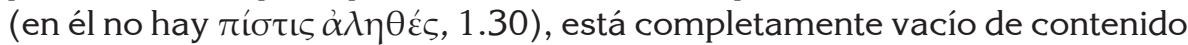

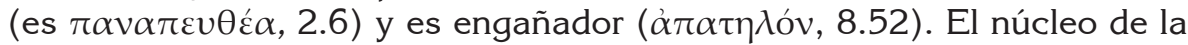
verdad (1.29) del primer discurso es el descubrimiento de la presencia necesaria del hecho de ser en todo lo que es (en efecto, los entes son entes porque poseen ser), manifestada en un primer momento por el desnudo

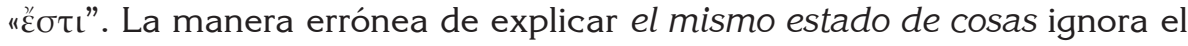
carácter necesario y absoluto del hecho de ser y se limita a colocar nombres sobre las cosas (nombres que se cree que son verdaderos, 8.39), derivados de opuestos que en realidad se anulan mutuamente (pues, aparte de ellos nada hay, 9.4). En este caso, la verdad está ausente; sólo hay opiniones, puntos de vista.

Ambos criterios o métodos son incompatibles, pero como la intención de Parménides es eminentemente didáctica (de ahí la utilización de la métrica épica homérica y de una serie de imágenes alegóricas hesiódicas fácilmente reconocibles por un griego de entonces), quien pretenda dedicarse a la filosofía debe estar al tanto también de teorías erróneas,

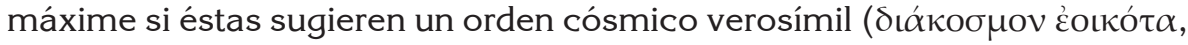

32 El término óđós tiene ya en época de Parménides el doble significado de "camino" y de "modo" o "manera". Ver Píndaro, Ol. VIII.13: "con la ayuda de los dioses, hay muchas maneras (ódoí) de triunfar". La palabra inglesa "way" hereda este doble significado. 
8.60), es decir, similar al verdadero (pero no verdadero). Exponer el error del discurso erróneo forma parte del discurso verdadero.

Vimos que en varias ocasiones Simplicio asimila "lo inteligible" al SerUno. Esta noción, inventada por Meliso ${ }^{33}$, no existe en Parménides. En su explicación del núcleo de la verdad, nada impide a Parménides pasar del

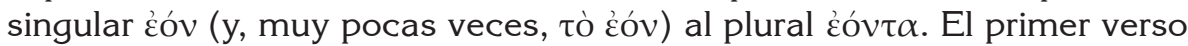
del fragmento 7 niega la posibilidad de que haya "cosas (="entes") que no

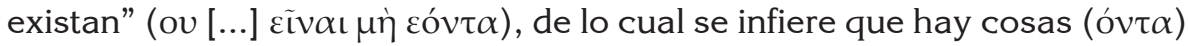
que existen, y en el fr. 4, en relación con el voũ $\varsigma$ (o sea, en un contexto para el cual es válida la asimilación de "ser" y "pensar" proclamada en el fr. 3)

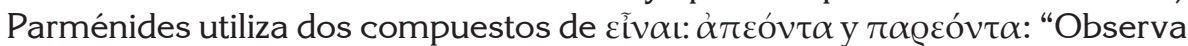
cómo las cosas ausentes están firmemente presentes para el pensamiento", y esto es así porque "no se puede obligar a lo que es a no estar conectado

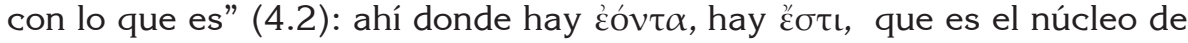
ćóv. Creer que el plural alude a "la multiplicidad sensible»" es caer en la dicotomía ontológica anacrónica que pretende explicar el Poema como si se tratara de una premonición de la línea dividida de Platón.

(b) De la oposición polar entre verdad (transmitida por un discurso,

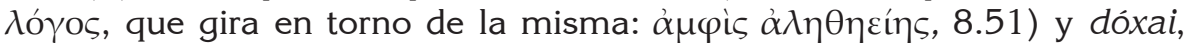
surge claramente que ambas nociones deben formar parte de un mismo enfoque: un enfoque gnoseológico. Más adelante, fundamentalmente en Platón, dóxa tendrá también valor ontológico ${ }^{35}$, y pasará a significar, también, "apariencia", pero en tiempos de Parménides, y especialmente antes, la traducción de dóxa por "opinión" se impone. Dóxa no es "lo que

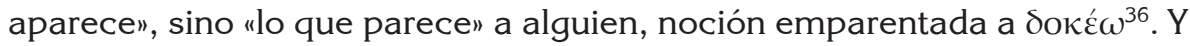

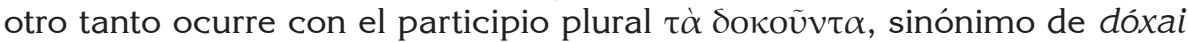

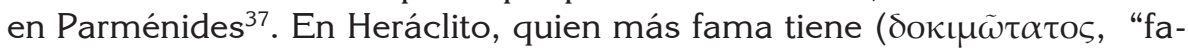
ma" es "lo que se dice" de alguien, no como alguien "aparece"), sólo co-

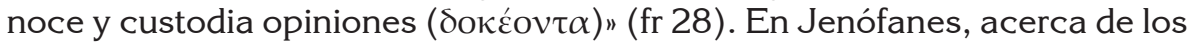
dioses, los hombres sólo tienen una opinión (ঠókos, sinónimo de dóxa) (fr. 34). Como observara Mourelatos, "solo en el caso en que los términos de

33 Ver el trabajo de BARnES citado en la nota 5.

34 Es el caso de Bollack (2006: 137), quien ve en este plural una alusión "a las cosmogonías". En un trabajo muy anterior este autor había ya propuesto colocar este fr. 4 en la segunda parte del Poema, porque "los dos participios están en plural" (1957: 56-71).

35 Un análisis exhaustivo del tema se encuentra en LAFRANCE (1981: passim).

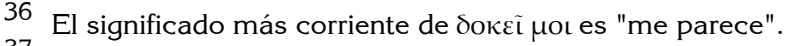

37 Dado que puede resultar extraño que la Diosa aconseje estar al tanto también de algo no convincente, como las opiniones (1.31), en el verso siguiente se aclara que, "no obstante" $(\varepsilon ̌ \mu \pi \eta \varsigma)$, hay que saber qué ocurriría si ellas se impusieran (1.32). El sujeto de ambos

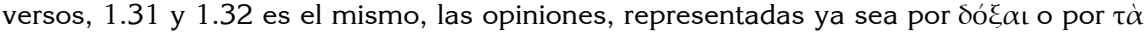

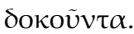


la raíz $\delta o \kappa$ - tienen sentido positivo, los ataques filosóficos a la doxa pueden ser mordaces ${ }^{38}$. Es exactamente lo que ocurre en el caso de Parménides.

Como dijimos, este conjunto de palabras dóxicas se encuentra ubicado en las antípodas del discurso ( $\lambda$ ó $\gamma o \varsigma$ ) verdadero, y por ello Parmenides lo califica de $\alpha \dot{\alpha} \alpha \tau \eta \lambda$ óv. Evidentemente, para quienes pretenden reivindicar la verosimilitud (a falta de la verdad) de la dóxa, la palabra $\alpha \operatorname{\tau } \alpha \tau \eta \lambda o ́ v$ resulta molesta. En nuestra post-modernidad, Popper, en un texto que nunca debió haber sido publicado, dice que Parménides se equivocó y que escribió $\alpha \pi \alpha \tau \eta \lambda$ óv cuando en realidad quiso escribir otra $\operatorname{cosa}^{39}$. Simplicio, con más sentido crítico que Popper, hace lo posible por matizar el término, pues también a él le molesta. En efecto, en la página 39 de su Comentario vuelve a citar los versos de Parménides que ya había reproducido en la página 30 (fr. 8.50-61), pasaje en el cual (en el verso 8.53) está el término $\alpha \pi \alpha \tau \eta \lambda$ óv, y luego de la cita textual afirma que "el discurso es llamado opi-

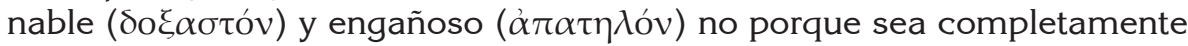
falso sino porque está como descendido de la verdad de lo inteligible al

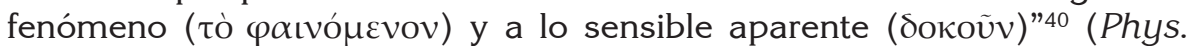
39.10). Ya W.D.Ross había observado que esta frase "es inconsistente con lo que el mismo Parménides dice en los versos recién citados, que implican que la segunda parte del Poema expone simplemente las opiniones falsas de los mortales" 41 .

Si dejamos de lado las evidentísimas influencias platónicas (el uso de

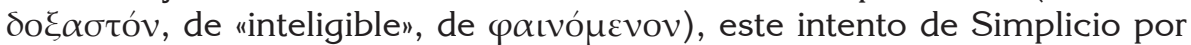
reivindicar, ya en Parménides, un "discurso" sobre las apariencias (término éste que reúne tò $\varphi \alpha$ เvó $\mu \varepsilon v o v$ y ठokoṽv), contiene, además, una imprecisión y el "olvido" de un pasaje del Sofista que ciertamente Simplicio conoce, aunque nunca citó. La imprecisión es la siguiente: Parménides jamás hubiese utilizado el término lógos (como hace Simplicio) para un conjunto de palabras "opinable" y "engañoso", ya que había reservado el término para su "discurso (lógos) confiable [...] acerca de la verdad" (fr. 8.50). El pasaje del Sofista "olvidado" es precisamente el comienzo de la sección dedicada al cuestionamiento de Parménides. En ese momento del diálogo, para justificar que el sofista sea un fabricante de "copias y de simulacros [de conocimientos]" (236c), debe sostenerse que éstos existan, o sea, que

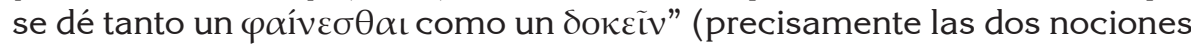

38 Mourelatos (2008:202).

39 Ver Popper (1998: 131-3).

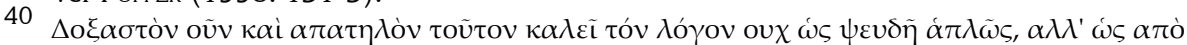

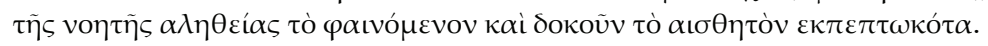

41 Ross (1924: 134). Debo esta referencia a uno de los anónimos evaluadores, sutil lector de una primera versión de este trabajo. 
que se encuentran en Simplicio en el pasaje recién citado: ‘ò $\varphi \alpha$ เvó $\mu \varepsilon v o v$ y ठокои̃v). Pero, dice Platón, para sostener esta posibilidad, hay que refutar a Parménides. Más claro imposible: las apariencias no tienen cabida en el Poema, pace Simplicio.

Además, cuando Simplicio intenta relativizar la noción de $\alpha \pi \alpha \tau \eta \lambda$ óv, parece no ver que en Parménides este término está opuesto polarmente a

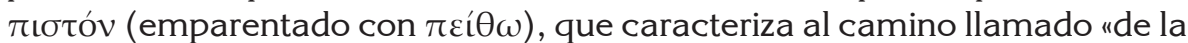
verdad". La proporción que Parménides sugiere es ésta: "verdad : opinion :: persuasión : engaño». Un discurso engañoso es opuesto a la Vía de la Verdad, y por eso Parménides no necesita utilizar la noción de "falsedad" ( $\psi \varepsilon \tilde{u} \delta \circ \varsigma$ ).

(c) La interpretación de la noción de dóxa por parte de Simplicio es un reflejo fiel del comentario de Aristóteles de los pasajes del Poema en los que Parménides presenta dos principios (si bien Aristóteles no usa nunca la palabra dóxa cuando se refiere a Parménides). No caben dudas de que las afirmaciones de Aristóteles (que evidentemente poseía el texto del Poema, puesto que lo cita) se refieren a la descripción que comienza en el verso 8.51, en la cual, según dice el mismo Parménides, se exponen una serie de dóxai. Para Parménides, éstas consisten, como comentará acertadamente Aristóteles, en el establecimiento ( $\kappa \alpha \tau \alpha \tau i ́ \theta \eta \mu \iota)$ de dos puntos

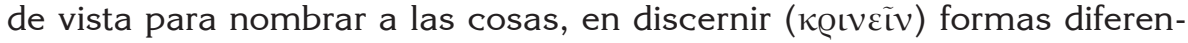
tes, y en colocar significaciones contrarias, separadas la una de la otra: el fuego o la luz, y la noche. Aristóteles reemplaza a veces la noche por la tierra o el frío, y basándose seguramente en pasajes del Poema que hoy no conocemos, asimila ambos principios al ser y al no-ser (De gen. et corr. 318b6). Dado que los principios postulados por las dóxai son realmente opuestos, no sería extraño que el mismo Parménides los haya asimilado a los dos opuestos fundamentales del Poema, ser y no-ser.

La descripción aristotélica de las dóxai es impecable, pero Aristóteles no ve -y Simplicio tampoco- que Parménides las atribuye a "otros", los mortales. No es importante identificar a esos "mortales", pero son "ellos" quienes propusieron dos principios opuestos, y, dice Parménides, "en eso se equivocaron" (8.54), probablemente porque hay un solo principio (otros pasajes del Poema dan a entender que se trata sólo de tò ćóv). Son "ellos" los que colocaron sobre cada cosa nombres significativos (óvo $\mu^{\prime}[. .$.$] ctíónuov)$

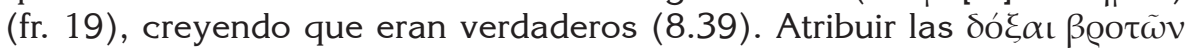
a Parménides es un gravísimo error. Ellas pertenecen a "los mortales", y Parménides llama "mortales" a una masa sin criterio ( $\alpha$ $\Leftarrow\llcorner\tau \alpha$, y que, por

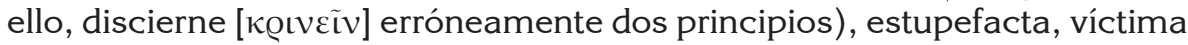
de lo que se dice, con ojos que no ven, oídos que no escuchan y con el pensamiento errabundo (6.5-7, 7.4-5). Dada la personalidad de los autores, no es de extrañar que ellos expongan sus doxai mediante un conjunto de

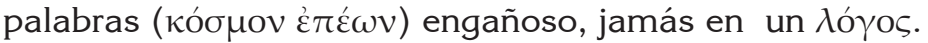




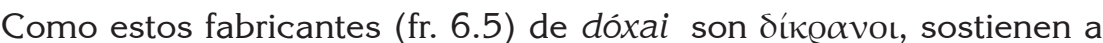
la vez que hay ser y que hay no-ser. Esta afirmación de la simultaneidad de contrarios encuentra un eco en la interpretación de Aristóteles según la cual Parménides "colocó dos causas y dos principios, el calor y el frío, a los que llamó fuego y tierra, y asignó el ser al fuego y el no-ser al otro" (Met. A.5.986b34-987a2), con la salvedad de que Parménides las colocó en las palabras engañosas de "otros".

Es para los mortales que nada saben que ser y no-ser son lo mismo (o sea, dos principios), y no lo mismo (o sea, opuestos) (6.6-7). Es porque son bicéfalos que los mortales son víctimas de la conjunción (6.5). El hombre que sabe (1.3), en cambio, es conducido por el camino de la disyunción: "se es, o no se es" (8.16), porque "es necesario existir totalmente, o no" (8.11). Mal puede ser un principio el no-ser (pace Aristóteles, Met.

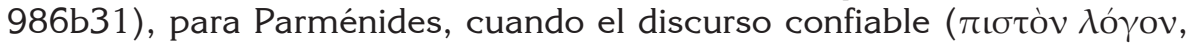

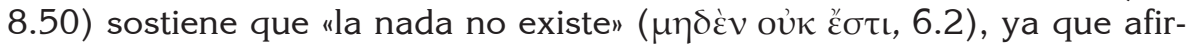
mar que "es necesario no-ser" (2.5) es $\pi \alpha v \alpha \pi \varepsilon v \theta \varepsilon ́ \alpha$ (2.6), porque "no se conoce ni se menciona lo que no es" (2.7-8). Como observara W.D.Ross, "dado el carácter negativo de la noche [...] no caben dudas de que Parménides no pudo sostener que ella era una de las $\mu о 0 \varphi \alpha i$ " 42

La Diosa, portavoz de Parménides, asocia las dóxai a un autor que no es ella misma; ella sólo las expone, para que el futuro filósofo esté al tanto de las mismas y sepa evitarlas (8.61). En 1.30 dice que "en las opiniones de los mortales no hay verdadera convicción", en 8.51 anuncia que va a exponer "las opiniones de los mortales", y en el fr. 19 dice que las cosas se produjeron de este modo según la doxa y que, respecto de ellas los hombres establecieron nombres significativos para cada una. Y otro tanto ocurre con la noción de $\gamma v \tilde{\omega} \mu \eta$ "punto de vista", sinónimo de doxa: "ellos establecieron dos puntos de vista..." (8.53). Como observara A.P.D.Mourelatos, es la atribución a "los mortales" la que da valor negativo a la doxa ${ }^{43}$. Basta leer la descripción despiadada que hace Parménides de "los hombres" en los fragmentos 6 y 7 para asombrarse de que aun hoy haya estudiosos que consideren que las "opiniones de los mortales" están avaladas por Parménides. La Diosa no usurpa un copywright que no le pertenece: siempre aclara quiénes son los autores de la teoría engañosa que ella utiliza como paradigma de cómo no deben explicarse las cosas.

La facilidad que consiste en pretender interpretar una filosofía muy difícil de comprender, como es la de Parménides, según los esquemas familiares aristotélico-platónicos lleva a Simplicio a cometer dos errores garrafales que los estudios parmenídeos heredan desde entonces:

42 Ross (1924: 134).

43 Mourelatos (2008: 202). 
(a) Para Simplicio, como la "parte" (?) del Poema llamada hoy "la Dóxa" se ocupa de las apariencias, y como todo cuanto es sensible (siempre según sus esquemas platónicos), pertenece al ámbito de las apariencias, las referencias parmenídeas al sol, la luna, los astros, la vía láctea, el cielo englobante, los sexos, etc., deben formar automáticamente parte de la doxa. Simplicio niega así a priori la posible existencia de una "física" e incluso de una cosmología auténticamente parmenídea, presentada por la Diosa (física que, evidentemente, no puede ser "engañosa"), no por los mortales. Pero, pace Simplicio, la Diosa exhorta a conocer esas realida-

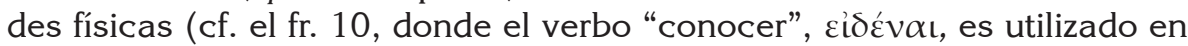
dos ocasiones, mientras que el contenido de la doxa no es cognoscible), y algunas respuestas a cuestiones "físicas" se encuentran en textos que Simplicio no cita: los actuales fr. 14, 15, 16, 17, 18.

Pero ocurre que en las versiones actuales del Poema, todo cuanto está ubicado entre el verso 52 del fragmento 8 y el fr. 19 es considerado como un bloque monolítico, llamado "la Doxa". En realidad, en este conjunto de cuarenta y nueve versos casi la mitad presenta teorías que no son ni engañosas ni falsas, o sea, que no corresponden a la significación que las dóxai tienen para Parménides, que son obra exclusiva de los mortales que nada saben. Afirmaciones como "[la luna], errante alrededor de la tierra, con luz prestada" (fr. 14), "[la luna] vuelta siempre hacia los rayos del sol" (fr. 15), así como la explicación "científica" del hecho insólito de que el voũs pueda divagar (fr. 16), nada tienen de engañoso ni de falso y no pertenecen a las dóxai de los mortales: en la reconstrucción actual del Poema ocupan un lugar que no les corresponde ${ }^{44}$.

(b) Dado que, según Simplicio, el Poema va de lo inteligible a lo sensible, Parménides opondría el pensamiento a la sensación. Estas dos maneras de acceder a la realidad de las cosas invitaron a Fülleborn a dividir el Poema, como vimos, en una "Vernunfterkenntniss vom Wesen der

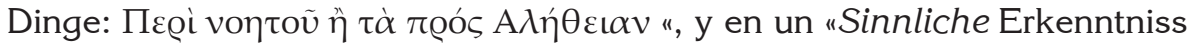

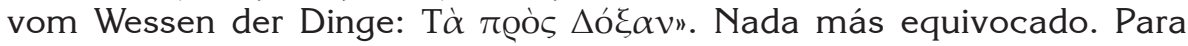
Parménides, todo depende del método que se siga. El método erróneo se vale de ojos, pero que no ven, de oídos, pero que no oyen (7.4), lo cual convierte a los mortales en sordos y ciegos (6.7). Pero a esta deficiencia de los sentidos se agrega un voũ errante (6.7) que les impide discernir: ellos son ökoıto y bicéfalos. La sensación puede ser bien utilizada: el oído, por ejemplo, permite "escuchar" ( $\dot{\alpha} \kappa o \tilde{v} \sigma \alpha \varsigma, 2.1)$ el $\mu \tilde{v} \theta$ o $\varsigma$ que enuncia la Diosa, así como "escuchar" ( $\alpha$ koú $\omega v, 8.52$ ) el engañoso discurso de la

44 En un trabajo publicado en 2010 no dudamos en hablar del "desmantelamiento de la doxa": CORDERO (2010: passim) 
Diosa, y los ojos sirven para "contemplar" $(\lambda \varepsilon \tilde{v} \sigma \sigma \varepsilon, 4.1)$ de qué manera el voũ s hace presente lo ausente.

Resultado de esta verdadera tarea de desinformación, surge del testimonio de Simplicio un Parménides incoherente que en más de una ocasión desorienta al mismo Simplicio, que es incapaz de ver que los problemas surgen de su propia interpretación. En varios pasajes de su comentario repite que, después de haber expuesto los principios del Ser-

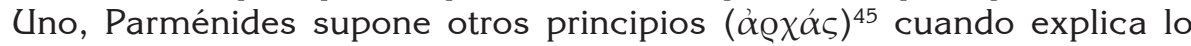

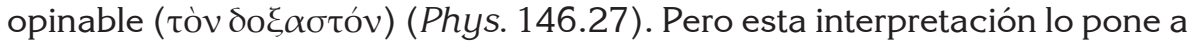
veces en un aprieto. Un caso paradigmático es su comentario del fragmento 19 , que se refiere sin duda alguna a la dóxa (está en él la palabra dóxa y la referencia a los mortales), y que no encaja en el rompecabezas simpliciano. En efecto, este fragmento desorienta a Simplicio, quien sin duda interpreta que el verbo "ser" tiene valor existencial en el verso 19.1. El contexto es el siguiente: después de haber citado los versos 50-2 del fr. 8, en los que Parménides anuncia que va a exponer las opiniones de los mortales, Simplicio agrega: "Y después de haber presentado la estructuración

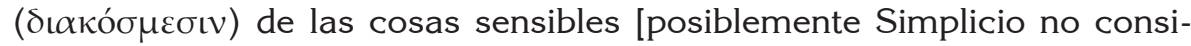
dera oportuno repetir los versos 53-59, que presentan dicha $\delta \iota \alpha \kappa o ́ \sigma \mu \varepsilon \sigma \iota \varsigma]$ agrega nuevamente:

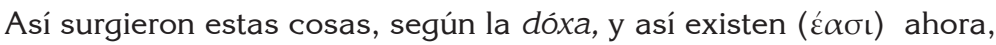
y luego, una vez desarrolladas, morirán;

a cada cosa los hombres le han puesto un nombre distintivo ${ }^{46}$

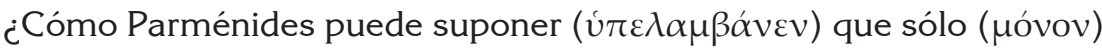
existen las cosas sensibles, precisamente él, que tanto filosofó sobre lo inteligible? [...] ¿Cómo pudo transponer lo inteligible a las cosas sensibles, él, que, por un lado, unió lo uno al ser inteligible, y, por el otro lado, elaboró claramente un orden cósmico con las cosas sensibles, que no fueron dignas de ser llamadas con el nombre de ser?" (De Caelo 558, 12). No caben dudas: es el verbo "ser" ( $(\varepsilon \sigma \iota)$, aplicado acá con valor existencial a lo sensible, que desconcierta a Simplicio.

Su asombro no habría sido tal si hubiese reflexionado sobre el hecho de que también los mortales que nada saben suelen utilizar el verbo "ser", pero, como no son capaces de captar su significado, suelen unirlo a su negación. Parménides lo dice: "Por eso son nombres cuanto los hombres

45 Mutatis mutandis, pareciera que Simplicio atribuye ya a Parménides la famosa frase que Groucho Marx escribirá siglos después: "He aquí mis principios. Si no le convencen, tengo otros".

46 Parménides, fr. 19. 
han establecido [Observar la similitud con los términos empleados en el fr. 19], creyendo que eran cosas verdaderas: [...] ser y no ser..." (fr. 8.3840). Si Parménides hubiese sido liberado de la autoría de la concepción expuesta al final del fragmento 8 y que continúa en el fr.9 acerca de los dos principios opuestos, luz y oscuridad, no habría contradicción alguna. Pero Simplicio insiste y persiste: "Los principios de las cosas físicas $(\tau \tilde{\omega} v$ $\varphi v \sigma \iota \kappa \tilde{\omega} v)$ son opuestos, y, cuando se ocupa de la doxa hace principios a lo caliente y lo frío; él los llama 'fuego' y 'tierra', y también 'luz' y 'noche oscura"" (Phys. 179. 29) 47 .

La descripción de Simplicio es exacta, pero Parménides atribuye esta tendencia errónea que consiste en proponer dos principios opuestos, a los mortales (y al no unificarlos "se han equivocado", 8.54): "Ellos establecieron dos puntos de vista..." (8.53). Además, la utilización de $\tau \tilde{\omega} v \varphi v \sigma t-$

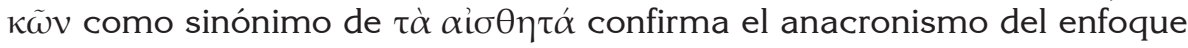
de Simplicio, que no sólo es post-platónico sino también post-aristotélico. Para un Presocrático estudiar $\tau \dot{\alpha} \varphi v \sigma \iota \kappa \alpha ́$ no tiene el sentido que tendrá en

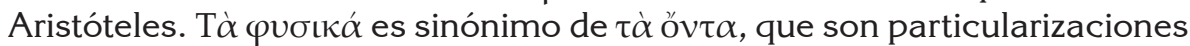
(y no "apariencias") de la púбıs, o sea, de aquello a lo cual Parménides aludirá por primera vez con un singular genérico, દ̇óv.

Curiosamente, Simplicio no parece advertir que quien afirmó de manera clara y distinta que Parménides no se ocupó de las apariencias fue el mismo Platón. Es verdad que Platón, pensador post-sofístico, cuya filosofía, como ya vimos, se apoya -aunque con matices- en un dualismo entre lo inteligible y lo sensible, o sea, entre el ser y las apariencias, no puede dejar de aplicar este esquema cuando estudia a los filósofos del pasado. Pero, como ya vimos, cuando se ocupa de Parménides debe reconocer que sólo si se lo refuta (refutación que él presenta como un intento de parricidio) se puede afirmar que hay en él, además del ser, algo así como el aparecer y el parecer (Sof. 236c). Estas nociones suponen que el no-ser existe, y Parménides dijo claramente que "nunca dominará esto: que haya

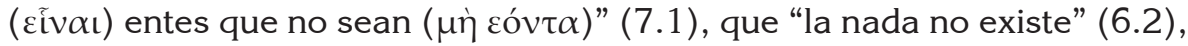
y que "no conocerás ni mencionarás lo que no es" (2.7-8). Si Parménides hubiera admitido la existencia de las "apariencias", Platón no habría tenido necesidad de escribir El sofista para refutarlo, ya que para justificar su crítica de la sofística se imponía demostrar que hay apariencias. Pero ocurre que Platón comprendió mejor al gran Eléata que su discípulo Aristóteles y que su gran citador neoplatónico, Simplicio.

$\overline{47}$ Ver también la página 30.20, citada supra. 
Apéndice (¿Moraleja?): Una reestructuración de las citas recuperadas de Parménides se impone

Dado el peso de la tradición, iniciada por el trabajo fundamental de Fülleborn y consagrada por H.Diels, uno de los más brillantes estudiosos de los textos de la Antigüedad, raros son los investigadores modernos que se atrevieron a intentar modificar el orden, considerado ya "tradicional", en que se estructuran las diecinueve citas recuperadas del Poema de Parménides.

Hasta hace unas décadas, los tímidos intentos de modificar esta estructura se habían limitado a derivar una cita de una "parte" del Poema a la otra ${ }^{48}$, y en 1955 R.Kent-Sprague había propuesto un "reordenamiento" de algunos textos en el interior de la parte llamada Alétheia ${ }^{49}$.

En los últimos años, a partir de una interpretación textual (es decir, aquella que surge de los escasos pero auténticos textos de Parménides y no de los comentadores) nosotros hemos escrito varios trabajos para sostener la necesidad de modificar el orden tradicional de las citas recuperadas. Nuestra posición fue expuesta por primera vez en 2007 en un Coloquio Internacional que organizamos en Buenos Aires, en un trabajo titulado "Parmenidean 'Physics' is not a Part of what Parmenides calls $\delta o ́ \xi \alpha$ " 50 . En escritos sucesivos reiteramos esta posición, especialmente en Parmenide scienziato?51 y en el "Post-Scriptum 2010" de la traducción al portugués de nuestro libro Siendo, se es. La tesis de Parménides ${ }^{52}$.

Esta tendencia comienza a interesar a los estudiosos. F.Santoro, sin duda inspirándose en Bicknell ${ }^{53}$, propuso también alterar el orden "tradicional" al colocar el fragmento 10, ubicado desde Fülleborn en la segunda "parte" del Poema, inmediatamente después del fragmento 1, como parte del programa de estudios que la Diosa propone a su oyente ${ }^{54}$

Pero el trabajo más documentado sobre el tema fue publicado en 2012 por Christopher John Kurfess. En una disertación de 220 páginas consagrada por completo a la cuestión, Restoring Parmenides' Poem ${ }^{55}$, el

$\overline{48}$ Por ejemplo, Bollack (1957: 56-71), propuso desplazar a la "segunda parte" el fragmento 4; LOENEN (1959) y HERSCHBELl (1970: 1-23), por su lado, fueron partidarios de transferir el fragmento 16 a la "primera parte", y p.j.Bicknell consideró que el fr. 10 debía seguir inmediatamente al fr. 1.

49 Kent-Sprague (1955: passim).

50 En Parmenides Venerable and Awesome (Plato, 'Theaetetus 183e), Proceedings of the International Symposium, ed. N.L.CORDERO, Las Vegas/Zurich/Athens, 2011, 95-113.

51 CORDERO (2008: 78-80)

52 Cordero (2011: 219-220).

53 Ver nota 48.

54 SANTORO ( 2011: 86).

55 KuRFESS (2012) 
autor confiesa inspirarse en nuestros trabajos ${ }^{56}$, si bien sigue, no obstante, un camino diverso: mientras que nuestra interpretación relativiza el valor exegético (no el documental, por cierto) de las fuentes (ya que, según nosotros, si el mismo Platón admitió no haber comprendido el sentido de las palabras de Parménides [Teeteto, 183e], otro tanto puede esperarse de intérpretes más alejados en el tiempo), Kurfess se apoya fuertemente en los testimonios, a los cuales analiza de manera ejemplar.

En resumen: los futuros investigadores tienen, en los escasos ciento cincuenta versos recuperados del Poema de Parménides, un material de estudio inagotable. En efecto, el Poema no ha revelado aún todos sus secretos.

\section{Bibliografía}

Baltussen, H. (2008) Philosophy and exegesis in Simplicius: the methodology of a commentator, Londres.

Barnes, J. (1979) "Parmenides and the Eleatic One", Archiv für Geschichte der Philosophie, 61, pp.1-21.

Bicknell, P.J. (1968) "Parmenides, Fragment 10", Hermes, 96, pp. 629-31.

Bollack, J.B. (2006) Parménide, de l'étant au monde, Paris.

Bollack, J.B. (1957) "Sur deux fragments de Parménide, fr. 4 et 16", Revue des Études Grecques, 70, pp. 56-71.

Brandis, C.A. (1813) Commentationum Eleaticarum. Pars prima: Xenophanis, Parmenidis et Melissi propriis philosophorum reliquiis exposita, Altona.

Cordero, N.L. B(1982) "La version de Joseph Scaliger du Poème de Parménides, Hermes, 110, pp. 391-398.

Cordero, N.L. (1988) "Zénon d'Élée, moniste ou nihiliste?", La Parola del Passato, 43, pp. 100-126.

Cordero, N.L. (2005) Siendo, se es. La tesis de Parménides, Buenos Aires.

Cordero, N.L (2008) et al. Parmenide scienziato?, ed. L.Rossetti-F.Marcacci, Sankt Augustin.

Cordero, N.L. (2010) “The 'Dóxa of Parmenides' dismantled", Ancient Philosophy, 30, p. 2.

Cordero, N.L (2011) "Parmenides venerable and awesome (Plato, 'Theaetetus 183e)" en Proceedings of the International Symposium, ed. N.L.Cordero, Las Vegas/Zurich/Athens, pp. 95-113.

CHERnISs, H. (1935) Aristotle's criticism of Presocratic philosophy, Baltimore.

56 KuRFESS (2012: X). 
Diels, H. (1882-5) Simplicii in Aristotelis Physicorum libros quattuor, ed. H.Diels, Berlín.

Diels, H. (1903) Die Fragmente der Vorsokratiker, Berlin.

Estienne, H. (1573) Poesis Philosophos, Ginebra.

Fülleborn, G.G. (1795) Fragmente des Parmenides, Zullichau, p. 104.

Gershenson, D.E.-GreEnBerg, D.A. (1962) "Aristotle confronts the Eleatics: Two arguments on 'The One'", Phronesis, VII.

Herschbell, J.R. (1970) "Parmenides' Way of Truth and B 16", Apeiron, 4, pp. 1-23.

KARSTEN, S. (1835) Philosophorum graecorum veterum praesertim qui ante Platonem floruerunt operum reliquiae. Volumen primum, pars altera: Parmenidis, Amsterdam.

Kent-SpRague (1955) "Parmenides. A suggested rearrangement of fragments in the Way of Truth", Classical Philology, 50, pp.124-6.

KERFERD, J.B. (1991) "Aristotle's treatement of the doctrine of Parmenides", Oxford Studies in Ancient Philosophy, ed. J.Annas, Supplem. Volume, Oxford.

KuRfess, C.J. (2012) Restoring Parmenides' Poem. Essays toward a new arrangement on the fragments based on a reassessment of the original sources, Pittsbourgh.

Lafrance, Y. (1981) La théorie platonicienne de la doxa, Montréal/París, Bellarmin/Les Belles Lettres.

Loenen, J.H.M.M. (1959) Parmenides, Melissus, Gorgias. A reinterpretation of Eleatic philosophy, Assen.

Mansion, S (1949) "Aristote, critique des Éléates", Revue Philosophique de Louvain, 47.

Mourelatos, A.P.D. (2008) The Route of Parmenides. Revised and Expanded Edition, Las Vegas/Zurich/Athens.

PoPper, K. (1998) The world of Parmenides, Londres/Nueva York.

Reinhardt, K. (1916) Parmenides und die Geschichte der griechischen Philosophie, Frankfut am Main.

Ross, W.D. (1924) Aristotle's Metaphysics, trad. y comentario W.D.Ross, Oxford.

SAntoro, F. (2011) Filósofos épicos I: Parmênides e Xenófanes, ed. F.Santoro, Río de Janeiro.

Stevens, A. (1990) Postérité de Être. Simplicius, interprète de Parménide, Bruselas.

Fecha de recepción: 21-01-2014

Fecha de aceptación: 17-08-2014 